\title{
Era multimodal e tecnológica: que recursos utilizar no ensino de línguas estrangeiras/adicionais?
}

\author{
Technological and multimodal era: which resources should we use in \\ foreign/additional language teaching?
}

\author{
Carolina Favaretto Santos ${ }^{1}$ \\ Cláudia Cristina Ferreira²
}

\begin{abstract}
Resumo
O desenvolvimento tecnológico tem promovido mudanças significativas na sociedade, tornando cada vez mais recorrente a utilização de diversos recursos e mídias digitais para o desenvolvimento da comunicação. Consequentemente, o ensino de línguas estrangeiras/adicionais tem se beneficiado dessas transformações, oportunizando reflexão de experiências favoráveis ao ensino, para alcançar maior efetividade e melhor qualidade no processo de ensino e aprendizagem. Nesse viés, este estudo tem por objetivo dialogar sobre conceitos e sugerir ações pedagógicas envolvendo tecnologia e multimodalidade no ensino de língua como prática social (ZAVALA, 2018). Para isso, são apresentados conceitos de letramento digital (LOPES, 2012; XAVIER, 2011), bem como de multimodalidade (COPE; KALANTZIS, 2000; ROJO, 2009), linguagem para a formação cultural e humana, bem como sobre a aplicação de recursos tecnológicos (LEFFA, 2016; MORAN, 2015) em atividades de ensino e aprendizagem de línguas estrangeiras/adicionais. Concluímos, com este estudo, que o letramento digital e a pedagogia dos multiletramentos permitem aos professores realizarem práticas pedagógicas diferenciadas, levando os alunos a otimizarem as habilidades linguísticas de maneira crítica e social, a fim de alcançar os objetivos propostos.
\end{abstract}

Palavras-chave: Processo de ensino e aprendizagem de inglês. Letramento digital. Multimodalidade.

\begin{abstract}
Technological development has promoted significant changes in society, making it increasingly common to use various resources and digital media for the development of communication. Consequently, the teaching of foreign/additional languages has benefited from these transformations, allowing reflection on experiences favorable to teaching, in order to achieve greater effectiveness and better quality in the teaching and learning process. In this bias, this study aims to discuss concepts and suggest pedagogical actions involving technology and multimodality in the teaching of language as a social practice (ZAVALA, 2018). For this, the following concepts will be mentioned: Digital Literacy (LOPES, 2012; XAVIER, 2011), as well as of Multimodality (COPE; KALANTZIS, 2000; ROJO, 2009), language for cultural and human formation, and the application of technological resources (MORAN, 2015; LEFFA, 2016) in teaching/learning activities of foreign/additional languages. We conclude with this study that Digital Literacy and The Pedagogy of Multiliteracies allow teachers to carry out differentiated pedagogical practices, leading students to optimize their language skills in a critical and social way, in order to achieve the proposed objectives.
\end{abstract}

Keywords: Teaching and learning process of English. Digital literacy. Multimodality.

\footnotetext{
1 Mestranda no Programa de pós-graduação Stricto Sensu - Mestrado Profissional em Letras Estrangeiras Modernas (MEPLEM). Universidade Estadual de Londrina (UEL), Londrina, Paraná, Brasil. Orcid: https://orcid.org/0000-0002-51370066. E-mail: carolinafavaretto7@gmail.com

2 Pós-Doutora em Estudos da Tradução pela Universidade Federal da Santa Catarina (UFSC). Professora associada de Língua Espanhola da Universidade Estadual de Londrina (UEL), Londrina, Paraná, Brasil. Orcid: https://orcid.org/0000-00034605-3733. E-mail: claucrisfer@sercomtel.com.br
}

LínguaTec, Instituto Federal de Educação, Ciência e Tecnologia do Rio Grande do Sul, Bento Gonçalves v. 5 , n. 2, p. 149-168, nov. 2020. 


\section{Considerações Preliminares}

O avanço tecnológico tem promovido mudanças no contexto educacional, no qual as possibilidades geradas a partir da inserção de tecnologias digitais de informação e comunicação (TDICs) se fazem cada vez mais presentes na sala de aula e fora dela. Professores e alunos, consequentemente, buscam acompanhar esse quadro, juntamente com suas transformações. Quando o foco é o ensino e a aprendizagem de uma língua estrangeira, essas mudanças estão conectadas ao progresso tecnológico. Isso vem acontecendo há algum tempo, não podemos esquecer que, uma vez, o próprio livro didático já foi considerado inovador. Padilha e Selvero (2013) mencionam que, juntamente com as alterações comunicativas no mundo moderno, o ambiente linguístico deveria ser recriado para que a aprendizagem se torne mais significativa para os alunos.

As gerações contemporâneas têm sido alvo dos benefícios e das influências das mídias digitais. Essas mídias possuem uma gama de possibilidades a serem utilizadas e adaptadas para melhorar 0 processo de aquisição de uma língua estrangeira. Novas tecnologias, quando integradas ao sistema educacional, podem criar novas realidades, ampliando conhecimento, despertando interesses e desenvolvendo habilidades e letramentos múltiplos (WARSCHAUER, 2006). Dessa forma, estudantes podem desenvolver maior motivação e facilidade ao aprender um novo idioma de maneira mais prazerosa, eficiente e significativa.

Por conseguinte, há estudos (PASSOS; SOARES, 2019; CENTENARO; REIS, 2017; CORRÊA; DIAS, 2016; ROJO, 2012) sendo conduzidos ao redor dessa temática, trazendo propostas de como adaptar práticas em sala de aula e integrá-las a tais recursos. De acordo com Belloni (2005, p. 07), "0 impacto do avanço tecnológico sobre processos e instituições sociais tem sido significativo e perceptível em vários níveis". O que não se esperava, entretanto, era que esse impacto cresceria abruptamente de maneira global e imediata devido a um inimigo comum e invisível a olho nu. Trata-se da pandemia do novo coronavírus ${ }^{3}$ (COVID-19).

Segundo a Organização Mundial de Saúde (OMS), "uma pandemia é a disseminação mundial de uma nova doença. $O$ termo é utilizado quando uma epidemia se espalha por diferentes continentes com transmissão sustentada de pessoa para pessoa" (AGÊNCIA BRASIL, 20204). Atualmente, há

\footnotetext{
${ }^{3}$ Do inglês Coronavirus Disease 2019 é uma doença infecciosa causada pelo coronavírus, da síndrome respiratória aguda grave (SARS-CoV-2). Mais informações disponíveis em: https://www.who.int/docs/default-source/coronaviruse/situationreports/20200306-sitrep-46-covid-19.pdf. Acesso em: 19 mai. 2020.

${ }_{4}$ Disponível em: https://agenciabrasil.ebc.com.br/saude/noticia/2020-03/coronavirus-saiba-o-que-e-uma-pandemia. Acesso em: 19 maio 2020.
}

LínguaTec, Instituto Federal de Educação, Ciência e Tecnologia do Rio Grande do Sul, Bento Gonçalves v. 5, n. 2, p. 149-168, nov. 2020. 
4.731.458 casos confirmados, incluindo 316,169 mortes $^{5}$. Diante deste inesperado cenário pandêmico, sob orientações da OMS,

[...] o Ministério da Educação (MEC) atendeu à solicitação feita pela Associação Brasileira de Mantenedoras de Ensino Superior (ABMES), bem como as orientações do Conselho Nacional de Educação (CNE), e publicou a portaria $n^{0} 343$, de 17 de março de 2020, que regulamenta as Instituições de Ensino a substituírem aulas presenciais pelo ensino a distância (EaD) pelo prazo de 30 dias ou, em caráter excepcional, podendo ser prorrogada enquanto durar a pandemia" (BRASIL, 2020, p. 39).

Com isso, instituições de ensino e professores subitamente enfrentam uma jornada de teletrabalho, onde passaram a

[...] vislumbrar um leque de novas oportunidades de utilização estratégicas das atuais Tecnologias de Informação e Comunicação (TIC), a fim de promover um processo formativo eficiente, capaz de levar conhecimento e oportunidade de aprendizagem para bilhões de alunos por meio dos recursos midiáticos oferecidos pela internet (JUNIOR; MONTEIRO, 2020, p. 02).

Vale salientar que nem todos os estudantes do país têm acesso a esses recursos midiáticos; sendo assim, a adoção em larga escala do ensino remoto se torna desigual e injusta. Segundo Yoshida (2020), "no Brasil, 30\% das pessoas ainda não têm conexão com a internet em casa. Entre os que acessam a rede, $97 \%$ utilizam o celular, que, muitas vezes, é defasado e não permite baixar programas de uma plataforma de ensino". Além disso, a Organização das Nações Unidas para a Educação, a Ciência e a Cultura (UNESCO, 2020) alerta que a situação ainda poderá se estender. Estes fatores contribuem para uma crescente exclusão digital, tópico presente em discussões acadêmicas que antecedem o período aqui discutido (BELLINI et al., 2010; DE MATTOS; CHAGAS, 2008; ALMEIDA; PAULA, 2004), porém não serão abordadas neste artigo porque nosso objetivo é outro.

A pretensão neste trabalho é, por conseguinte, lançar um olhar mais cuidadoso sobre os impactos causados aos alunos e aos professores devido tanto ao avanço dos recursos tecnológicos, quanto à atual conjuntura perante a pandemia do COVID-19. A partir disso, buscamos propor atividades pedagógicas relevantes ao ensino de língua estrangeira, sob a ótica dos Multiletramentos (COPE; KALANTZIS, 2000; CAZDEN et al., 1996) e a utilização de narrativas visuais (RODRIGUES, 2012) como instrumento de ensino. Tais atividades podem ser adaptadas para aulas remotas, devido à crise que assola nosso país. No entanto, seguimos na esperança de que a situação se normalize para que as https://covid19.who.int/?gclid=CjwKCAjwh472BRAGEiwAvHVfGsEgNY7DeSwIDwIRsviB1sJZjGvK8IvYBmbgqbc2pQltINDOe XJ-hRoCCRIQAvD_BwE. Acesso em: 19 maio 2020. 
mesmas possam ser executas em sala de aula presencial novamente, onde há um relativo aumento de acessos, estreitando, ao menos parcialmente, a lacuna social existente no Brasil.

Este artigo é composto de uma seção de fundamentação teórica organizada em três aspectos que expõem os principais conceitos e construto teóricos para este estudo. Na segunda seção são apresentadas propostas pedagógicas para uma articulação entre os avanços da era tecnológica multimodal e práticas em sala de aula. Por fim, a última seção comenta a respeito de possíveis contribuições deste texto para estudos futuros.

\section{Referencial teórico}

2.10 ensino de línguas estrangeiras/adicionais ${ }^{6}$ na contemporaneidade

No cenário atual, uma língua estrangeira/adicional pode assumir papel fundamental na transformação social (ROCHA; TíLIO, 2009). Para tanto, é essencial que o ensino de línguas seja orientado mediante uma perspectiva crítica (NORTON; TOOHEY, 2004), visando à participação do indivíduo como cidadão ativo na sociedade (LEFFA; IRALA, 2014). Desse modo, enxerga-se a linguagem como prática social no processo de ensino e aprendizagem de um novo idioma, tendo em vista que é por meio do processo de interação na/pela linguagem que o homem se constitui como sujeito e, portanto, torna-se um multiplicador de ideias (BENVENISTE, 2008).

Desta forma, Bakhtin (2000) assinala que todas as esferas da atividade humana, por mais variadas que sejam, estão sempre relacionadas com a utilização da língua. Isto posto, a linguagem deve ser exercida enquanto uso e interação social. Vygotsky (1984) pontua que a linguagem contribui para a compreensão do ser humano social e histórico. Além disso, o mesmo diz que a língua, enquanto fala, tem como função primordial a comunicação e o intercâmbio social. Isto posto, entende-se que língua e cultura são indissociáveis, pois: "uma das principais formas de expressão de um povo é sua língua, mas a língua anda de mãos dadas com a cultura" (DURÃO, 2002, p. 06). Nesse viés, assinalamos que cada língua possui seus próprios valores culturais, sendo necessário seu entendimento para obter melhor resultado na comunicação. Como cultura, utilizaremos a definição oferecida por Araújo e Figueiredo (2015, p. 3), que a caracterizam como sendo um "conjunto de padrões, de valores, experiências, crenças

\footnotetext{
${ }^{6}$ De acordo com Leffa (2014, p. 31), uma língua estrangeira é a língua estudada que "não é falada na comunidade em que mora 0 aluno"; já língua adicional significa aprender uma língua quando já se sabe uma outra. Por isso, quando 0 aluno aprende uma língua, ela sempre será adicional, considerando a língua materna do falante, porém, essa nova língua pode não ser necessariamente estrangeira. Devido a isso, optamos por utilizarmos o termo língua estrangeira/adicional neste estudo. 0 termo adicional remete a um apagamento de fronteiras entre línguas, vistas num viés somatório e desprovido de preconceito, distanciamentos ou hierarquias.
} 
de uma sociedade, organização, grupo, [...] parte essencial dos indivíduos passada de geração a geração".

\begin{abstract}
Nesse sentido, o componente cultural desempenha um papel importantíssimo no processo de ensino e aprendizagem das línguas estrangeiras. Nas palavras de De Greve e Van Passel (1971) "ensinar uma língua significa ipso facto ensinar a cultura, já que em sua condição de fenômeno, a língua representa em essência um dos principais aspectos da cultura de uma comunidade." Portanto, aprender uma língua nova significa dominar "não só o conhecimento das propriedades formais da língua como sistema, mas também um conhecimento do uso social da língua e de seu funcionamento nas situações comunicativas diárias" (Gimeno Menéndez, 1993) (DURÃO, 2002, p. 6-7).
\end{abstract}

Ao enxergar a língua como um elemento social, inerente à cultura do falante, percebe-se que 0 ensino de uma língua estrangeira/adicional não deve limitar-se ao âmbito gramatical, estrutural e fonético, por exemplo. É preciso abranger aspectos culturais durante as aulas, colaborando para a ampliação de visão de mundo e criticidade do aluno. $O$ trabalho com matizes culturais no ensino de línguas propicia 0 desenvolvimento da interculturalidade, onde há oportunidade de reflexão por meio da "exploração de um espaço intermediário, pelo contraste entre a língua/cultura própria e a língua/cultura alvo" (GIMENEZ, 2001). Chamamos a atenção para a contribuição de matizes culturais atreladas ao processo de ensino e aprendizagem para "minimizar ou erradicar visões fragmentadas, generalizações, estereótipos e preconceitos no que tange à diversidade em geral" (FERREIRA, 2020, p. 19).

Por sua vez, Leffa e Irala (2014) discorrem sobre o processo histórico-metodológico do ensino de línguas, onde observou-se que a língua possui e pode ser ensinada por meio de três dimensões. $A$ primeira dimensão é chamada de dimensão sistêmica, onde o foco é no código da língua. Esse primeiro estágio é majoritariamente estrutural e instrumental. A segunda dimensão é a funcional, com foco na função linguística. Nesse sentido, pode-se entender em quais situações e/ou contextos a língua pode ser aplicada. Entretanto, a última dimensão é a que mais nos interessa na perspectiva de língua como prática social: a dimensão crítica, cujo objetivo é provocar a mudança no indivíduo e, consequentemente, no mundo onde ele habita por meio da linguagem.

Podemos concluir que a língua deve ser organizada para trabalhar com diferentes componentes. Liberali (2009) traz o conceito de Atividade Social para tentar alcançar o objetivo de 0 aluno agir no mundo por meio da linguagem. Ela se baseia no princípio de que a língua deve ser um reflexo e prática da "vida que se vive" (MARX; ENGELS, 2006, p. 26). Dialogando com Leffa, Liberalli defende o ensino como forma de transformar as pessoas para uma melhor coexistência. Alinhada à Teoria da Atividade de Engestrom (2002), a Atividade Social propõe o ensino por intermédio de um artefato cultural, o qual pode ser idealizado no uso de recursos tecnológicos multimidiáticos. 


\subsection{TDICs e Letramento Digital}

A mais nova geração de aprendizes, conhecida como Geração Alpha $(\mathrm{G} \alpha)$, é parte integrante do grupo de alunos pertencentes ao provisório modelo educacional virtual, mediado por computadores e ambientes virtuais de aprendizagem (AVA). Logo, conclui-se que aquilo que era antes uma razão para aperfeiçoamento didático e pedagógico, hoje se tornou uma necessidade imediata de mudança e atuação. Entretanto, sabemos que essa não é uma tarefa fácil, visto que nossa sociedade apresenta desigualdade quanto à disponibilização de recursos tecnológicos tanto para o corpo docente, quanto para os alunos; ambos exercendo seu respectivo papel educacional direto de suas residências. Isto posto, a inserção de tecnologias e atividades que fomentem o pensamento crítico em sala de aula (momentaneamente virtual) podem trazer uma notável diferença e melhora no processo de aquisição de uma língua.

Freitas (2010) relata em suas pesquisas que, apesar de algumas escolas oferecerem acesso e disponibilidade a recursos tecnológicos, não é o suficiente para que professores os integrem em suas práticas diárias devido a dificuldades apresentadas na aplicação e execução dos mesmos. Pierre Lévy (2010, p. 159) notabiliza a questão da relação entre as tecnologias e a formação profissional ao assinalar que "pela primeira vez na história da humanidade, a maioria das competências adquiridas no início de seu percurso profissional estarão obsoletas no fim de sua carreira". A partir desta constatação, podemos visualizar a necessidade da formação continuada no cotidiano do profissional docente, como pontua Silva (2012, p. 05): "na formação de professores, os formadores precisam incluir nas agendas espaço para que essas demonstrações aconteçam de forma a atenuar o impacto inicial daqueles que ainda não têm tanta familiaridade com as novas tecnologias".

Ocasionalmente, diante de um cenário contemporâneo e digital, os professores de línguas estrangeiras/adicionais podem se sentir um pouco confusos e inseguros ao utilizarem certas plataformas e programas. Contudo, para atingir-se uma maior efetividade de resultados no ensino, os docentes têm como parte integrante de seu trabalho buscar "fazer com que essa maneira inovadora, certamente percebida como caótica e desordenada, faça sentido para os alunos" (CELANI, 2004, p. 50-51). Dessa forma, os alunos podem se sentir mais motivados e conectados com o conteúdo apresentado.

Como consequência da evolução tecnológica, de mudanças consideráveis nas características de membros das novas gerações e da panorâmica mundial atual, professores demandam maior atenção quanto à utilização dos recursos digitais disponíveis. Não basta somente ter o conhecimento básico sobre instruções e usos de certo equipamento ou ferramenta; é preciso analisar criticamente como esse 
instrumento pode beneficiar na maneira como a língua é ensinada e transposta, por isso destacamos que alunos e professores em circunstâncias atuais necessitam ser digitalmente letrados. Lopes (2012) conceitua Letramento Digital da seguinte maneira:

\footnotetext{
O termo letramento digital pode ser entendido sob uma ótica que vai além da capacidade de decifração de um sistema de signos específicos e veiculados pela linguagem hipermidiática dos textos eletrônicos. Letramento digital remete a outras dimensões discursivas que, por sua vez, levam a uma percepção mais crítica da produção, dos modos de distribuição e circulação da cultura cibernética na sociedade (LOPES, 2012, p. 9).
}

Corroborando este mesmo pensamento, Dotta et al. (2013), destacam que, apesar da tecnologia permitir e oferecer um grande acesso à informação, é papel do professor promover condições de aprendizagem para que sua utilização atinja objetivos educacionais. Com o avanço da tecnologia e o surgimento de Tecnologias Digitais da Informação e Comunicação (TDICs), a sociedade assumiu um novo perfil, onde a rapidez de informações modificou o modo de pensar e de viver das pessoas (SILVA, 2012). Além disso, atualmente, "a tecnologia, antes vista como algo que tirava o sujeito do convívio social, tornou-se cada vez mais utilizada e pensada para benefício coletivo" (JUNIOR; MONTEIRO, 2020, p. 3). Posto que "o grau de letramento digital do sujeito cresce à medida que aumenta o domínio dos dispositivos tecnológicos que ele emprega em suas ações cotidianas" (XAVIER, 2011, p. 04), o professor pode enriquecer suas práticas em prol das exigências coletivas ao se tornar digitalmente letrado. Essas reflexões atuaram como elementos motivadores para a elaboração de sugestões pedagógicas posteriormente aqui apresentadas, na esperança de poder contribuir com professores de línguas estrangeiras/adicionais em tempos tão complexos e adversos.

Diante dos últimos acontecimentos, as TDICs têm provocado efeitos significativos para 0 processo de escolarização, principalmente em relação às várias possibilidades de trabalho em contexto escolar, que permitem e facilitam o processo de ensino e aprendizagem. Elas ocasionam diversas inovações, "sobretudo no que tange as diferentes possibilidades de transformar tais ferramentas em salas de aulas virtuais, que possibilitam a interação de alunos e professores" (JUNIOR; MONTEIRO, 2020 , p. 4). Ademais, algumas delas são mais próximas das atividades cotidianas dos alunos, como vídeos, músicas, jogos ou até mesmo a internet, em geral (GARCIA; SILVA; FELÍCIO, 2012, p. 142).

Segundo Barros et al. (2012), o avanço tecnológico não se aplica somente aos usos de novos elementos; ele também altera comportamentos, não somente individuais, mas de todo um grupo social. Partindo desse princípio, entende-se que recursos tecnológicos podem trazer consigo o aprimoramento linguístico, pois, com o advento da internet, muitos meios midiáticos encontram-se em língua estrangeira, colocando o indivíduo em exposição e contato direto com outras línguas. 
É indiscutível que as novas tecnologias transformam a sociedade e os indivíduos, interferindo diretamente no seu desenvolvimento. As pessoas têm modificado a sua forma de se comunicar, ler, escrever, agir, interagir, compreender e se relacionar através de diferentes tecnologias, que também estão presentes no cotidiano das escolas, na vida e nas práticas sociais de alunos e de professores (MARQUES, 2016, p. 109).

Em relação a mudanças presentes na vida social de alunos e professores, esses avanços trouxeram consigo um novo contexto e ambiente de aprendizagem. Plataformas e espaços digitais se manifestam grandemente na educação. Leffa (2016) caracteriza um procedimento implantado por essas novas práticas: a sala de aula invertida (SAI). De acordo com o autor, esse método propõe um tipo de aprendizagem em que 0 aluno age e reflete sobre o conhecimento que está sendo construído por meio de interações e práticas sociais. Portanto, é agindo e refletindo, juntamente com o próximo, que o aluno tem a chance de "criar e transformar sua realidade, base essencial da educação" (LEFFA, 2016, p. 18). Esse modelo pode ser benéfico, pois é um modelo pedagógico no qual o tradicional modelo de ensino com o professor em sala e os elementos da tarefa de casa são invertidos. Vídeos curtos sobre a aula são vistos em casa antes da aula presencial, enquanto o tempo em sala de aula é dedicado para a realização de exercícios, projetos e discussões (BERGMANN, 2012).

\subsection{Pedagogia dos Multiletramentos}

A ênfase em meios semióticos tradicionais, como o texto impresso ou os letramentos da letra, está caindo em desuso. Em uma sociedade conectada, indivíduos convivem com outras linguagens, como fotos, imagens, vídeos, músicas, animações e diagramas. Logo, novos contextos introduzem novos tipos de aprendizes. Estes, por sua vez, carecem de novos tipos de aprendizagens, exigindo, portanto, outra pedagogia (ROJO, 2016): a Pedagogia dos Multiletramentos:

Cope e Kalantzis (2006) chamam a essa pedagogia "pedagogia dos multiletramentos" que definem como sendo uma pedagogia por design, na qual os estudantes precisam se apropriar dos designs digitais disponíveis, isto é, precisam, é claro, ter conhecimento prático e competência técnica para ser um "usuário funcional", mas somente isso não basta: é preciso também ser um leitor, um analista crítico desses designs disponíveis (textos, infográficos, vídeos de diversos tipos, esquemas, imagens estáticas, games etc.). Mas uma pedagogia dos multiletramentos não se esgota nos designs disponíveis: ela busca conhecê-los e analisá-los criticamente para, a partir deles, chegar ao redesign, isto é, a uma produção que se apropria do disponível conhecido para "criar sentidos transformados e transformadores" (ROJO, 2016, p. 09-10). 
O New London Group (CAZDEN, et. al., 1996) discorre sobre a Pedagogia dos Multiletramentos ao relatar que ela apareceu como uma proposta para uma nova prática educacional que abrange mudanças relacionadas à modernidade, como novos hábitos e novas maneiras de se comunicar. 0 grupo adverte métodos tradicionais que utilizam o texto escrito como seu único instrumento didático, já que é praticamente impossível encontrar somente um meio monomodal de comunicação nos dias de hoje. Em contrapartida, eles encorajam o emprego de textos multimodais, os quais são mais suscetíveis a alcançar sucesso ao explorar a capacidade humana de se expressar inteiramente por meio da linguagem. (CAZDEN et. al., 1996).

Ao sintetizar conceitos relacionados à nova pedagogia em questão, Brener (2018) reporta que 0 termo "multiletramentos" faz referência a duas dimensões: multilíngue e multimodal. A primeira diz respeito a diversidades sociais, como o uso da língua entre as minorias, diferenças discursivas, diferenças identitárias e diferentes letramentos em relação à diversificação cultural. A segunda, chamada de Multimodalidade, prega que a construção do conhecimento é ativa e dinâmica, realizada por meio de diferentes meios de comunicação e interação com o mundo e os outros.

Kress (2010) define Multimodalidade como sendo uma interação entre a fala, a escrita, a leitura e outras maneiras de criar significado. Essa cooperação envolvendo meios multissemióticos se encontra exposta atualmente, sobretudo com o crescimento contínuo das TDICs. Redes sociais como Facebook, What's App, Instagram e Twitter desempenham influente papel no curso comunicativo. Consequentemente, eles intervêm diretamente no comportamento dentro (e fora) de sala de aula, assim como na comunidade social em geral, reafirmando a indispensabilidade do exercício de reflexão sobre práticas pedagógicas na contemporaneidade.

\section{Propostas Pedagógicas}

Com base nos preceitos teóricos explorados, apresentamos algumas propostas de atividades pedagógicas englobando as tecnologias digitais de informação e comunicação, à luz dos multiletramentos no ensino de línguas, utilizando Narrativas Visuais como instrumento de ensino. 0 objetivo do desenvolvimento dessas atividades é propiciar oportunidades de interação entre aluno/aluno, aluno/professor e aluno/mundo, além de promover o uso de meios multissemióticos, a fim de resultar em um possível exercício da cidadania por meio da linguagem.

Há várias denominações para o termo Narrativas Visuais: livro sem texto; álbum de figuras; livro mudo; texto visual; livro sem palavras; livro-imagem e livro de imagem. Rodrigues (2012, p. 66) define narrativas visuais como sendo "[...] um texto completo e não necessita de reforço verbal, e sim de 
interpretação, como qualquer texto literário". Ressaltamos que definição que baseou este trabalho, entretanto, foi a seguinte:

[...] toda e qualquer narrativa (literária ou não) que é 'contada'/narrada ou ilustrada somente por meio de texto visual, ou seja, há ausência do texto verbal. Se, por acaso, o texto verbal se fizer presente, ele é representado e lido como texto visual, não como letras e palavras. Aqui 0 texto verbal terá o papel de ilustração, tão somente. Trata-se, portanto, de um texto aberto, cujo final do livro não implica, necessariamente, o final da história, o qual possibilita maior autoria, liberdade criativa/leitora e participação ativa do leitor que pode pertencer a qualquer faixa etária, sem restrições (FERREIRA, 2019, p. 139-140).

Alguns dos notáveis benefícios do uso de narrativas visuais em práticas pedagógicas condizem com a vantagem das obras abarcarem qualquer faixa etária e apresentarem flexibilidade para serem trabalhadas no ensino de qualquer idioma. Por serem constituídas majoritariamente por imagens, a leitura pode ser feita com vários públicos diferentes. Entre alguns dos objetivos que podem ser alcançados com o uso desse gênero no ensino de língua estrangeira/adicional, estão o aguçar da curiosidade, aumento do nível de interpretação textual, e estímulo do pensamento crítico por meio da leitura de imagens, ao fazer uso de recursos tecnológicos e multimodais em sala de aula.

De modo consequente, buscamos meios tecnológicos, digitais e multimodais como critérios de elaboração de sugestões de atividades, as quais apresentam obras de narrativas visuais como instrumento de uso da língua. A obra escolhida foi Omar e o Mar do autor mineiro Claudio Martins ${ }^{7}$. Nesta obra, um menino (Omar), sem sair de seu quarto, viaja pelos quatro cantos do mundo com seu cachorro, somente com o auxílio da imaginação. Ao longo das vinte e quatro páginas do livro, ilustrações retratam os destinos visitados pelos personagens, narrando a história a partir de suas cores, tons e formas. Assim sendo, desenvolvemos oito propostas didáticas, formando uma sequência de aulas com atividades relacionadas ao agir do aluno no mundo em que se vive. Almejou-se encorajar a interculturalidade e 0 exercício do pensamento crítico por intermédio da linguagem, tendo como base as ilustrações e os lugares representados no livro.

A finalidade dessa proposta é prover sugestões de mecanismos digitais que possam auxiliar no processo de ensino e aprendizagem de uma língua estrangeira/adicional sob a perspectiva dos multiletramentos, visando promover possibilidades de interação e uso da língua alvo. Para isso, mergulhamos no universo dos Repositórios Educacionais Abertos (REA), aventurando-nos no uso de Objetos Digitais de Aprendizagem (ODA). Nessa ótica, pode-se entender REA como sendo:

\footnotetext{
${ }^{7}$ Disponivel para aquisição em: https://www.amazon.com.br/Omar-Mar-Cl\%C3\%A1udio-Martins/dp/8573194480.
} 
[...] materiais de ensino, aprendizado e pesquisa em qualquer suporte ou mídia que estão sob domínio público ou são licenciados de maneira aberta, permitindo que sejam acessados, utilizados, adaptados e redistribuídos por terceiros. $O$ uso de formatos técnicos abertos facilita 0 acesso e reuso potencial dos recursos. Os REA podem incluir cursos completos, partes de cursos, módulos, guias para estudantes, anotações, livros didáticos, artigos de pesquisa, vídeos, instrumentos de avaliação, recursos interativos como simulações e jogos de interpretação, bancos de dados, software, aplicativos (incluindo versões para dispositivos móveis) e qualquer outro recurso educacional de utilidade. Muitos REA - mesmo que possam ser compartilhados por meio de formatos digitais - também podem ser impressos (UNESCO/COL, 2011 apud AMIEL; SANTOS, 2013, p. 02)

Os repositórios educacionais disponibilizam diferentes formatos de recursos pedagógicos tais como textos, livros, multimídia, dentre outros, para serem implementados em sala de aula. Em ambientes virtuais, os materiais disponíveis e utilizados com mais frequência são os Objetos de Aprendizagem Digitais (OAD). Araújo (2013, p. 179) define-os como sendo "recursos digitais reutilizáveis que se prestam a servir como ferramentas de ensino em diversos contextos educacionais". Braga (2014) preconiza que os OAD podem demonstrar vantagens consideráveis quando aliados ao processo educativo, no entanto, depende da clareza dos objetivos que se deseja alcançar, assim como da definição de estratégias para a utilização desses objetos por parte do professor.

Perante a concepção de língua como prática social (ZAVALA, 2018) e os princípios da Atividade Social (LIBERALI, 2009), ao final de cada proposta, os alunos são convidados a participar da realização de uma ação social perante a comunidade em que habitam. Desse modo, a partir do uso de diferentes ferramentas digitais, os alunos teriam a oportunidade de desempenhar seu papel cidadão em atividades sociais na língua alvo. Para fins representativos, o público alvo selecionado para esta proposta são aprendizes de inglês como língua estrangeira/adicional, com nível linguístico A2-B1 de acordo com o Quadro Europeu Comum de Referência Para Línguas ${ }^{8}$. Vale aqui salientar que as atividades propostas são passíveis de adaptações se o educador assim julgar necessário.

Uma síntese dos planos de aula equivalentes às atividades foi organizada categoricamente no Quadro 1 para fins instrutivos, contendo: número da aula, título da aula, tema abordado, recursos multimodais utilizados, objetivo pedagógico, proposta de ação social e sugestões de artefatos digitais que podem ser utilizados durante a aula. Em seguida, o Quadro 2 disponibiliza, de forma concisa, informações sobre as ferramentas utilizadas em cada aula.

\footnotetext{
${ }^{8}$ Disponivel em: https://www.cambridgeenglish.org/exams-and-tests/cefr/
} 


\begin{tabular}{|c|c|c|c|c|c|c|}
\hline $\begin{array}{l}\mathbf{A} \\
\mathbf{U} \\
\mathbf{L} \\
\mathbf{A}\end{array}$ & TÍTULO & $\begin{array}{c}\text { TEMA } \\
\text { ABORDADO }\end{array}$ & $\begin{array}{c}\text { RECURSOS } \\
\text { MULTIMODAIS }\end{array}$ & OBJETIVO & $\begin{array}{c}\text { PROPOSTA DE AÇÃO } \\
\text { SOCIAL }\end{array}$ & OAD e REA \\
\hline 1 & $\begin{array}{l}\text { Omar in New } \\
\text { York }\end{array}$ & $\begin{array}{l}\begin{array}{l}\text { Cenário } \\
\text { Yorkino; }\end{array} \\
\text { Discussões sobre o } \\
\text { ocorrido em 11/09 }\end{array}$ & $\begin{array}{l}\text { Música: Empire State of } \\
\text { Mind de Alicia Keys }\end{array}$ & $\begin{array}{l}\text { Trabalhar } \\
\text { intercultura-lidade }\end{array}$ & $\begin{array}{l}\text { Criação de um Padlet com } \\
\text { mensagens motivadoras para } \\
\text { as famílias atingidas pela } \\
\text { tragédia. }\end{array}$ & $\begin{array}{l}\text { a) Lyrics training }{ }^{10} \\
\text { b) Vídeo do Youtube } \\
\text { c) Padlet }\end{array}$ \\
\hline 2 & $\begin{array}{l}\text { Omar around } \\
\text { Europe }\end{array}$ & $\begin{array}{l}\text { Costumes de alguns } \\
\text { países europeu } \\
\text { Imigração no } \\
\text { contexto atual. }\end{array}$ & $\begin{array}{l}\text { Fotos e imagens; } \\
\text { Artigos de notícias; } \\
\text { Pesquisa em Websites } \\
\text { governamen-tais. }\end{array}$ & $\begin{array}{l}\text { Desconstruir } \\
\text { estereótipos }\end{array}$ & $\begin{array}{l}\text { Elaboração de um folheto } \\
\text { informativo para auxiliar } \\
\text { imigrantes ao adentrarem um } \\
\text { país no qual não falam o } \\
\text { idioma oficial. }\end{array}$ & $\begin{array}{l}\text { a) Google Earth e } \\
\text { Google StreetView } \\
\text { b) Canva } \\
\text { c) TED-Ed Blog }\end{array}$ \\
\hline 3 & Omar visits Asia & $\begin{array}{l}\text { Impacto causado } \\
\text { pelos avanços } \\
\text { tecnológicos. }\end{array}$ & $\begin{array}{lr}\text { Charges e } & \text { Tirinhas } \\
\text { cômicas sobre o uso de } \\
\text { tecnologia } \\
\text { atualidade. }^{11}\end{array}$ & $\begin{array}{lr}\text { Refletir } & \text { sobre } \\
\text { possíveis benefícios } \\
\text { oportunizados pela } \\
\text { tecnologia como } \\
\text { soluções r para } \\
\text { problemas }\end{array}$ & $\begin{array}{l}\text { Elaboração de uma tirinha } \\
\text { cômica ou charge com o } \\
\text { tema: Uso da tecnologia na } \\
\text { contemporanei-dade. } \\
\text { Compartilhar nas redes } \\
\text { sociais: Facebook e Twitter }\end{array}$ & $\begin{array}{l}\text { a) Pixton } \\
\text { b) Storyboard that }\end{array}$ \\
\hline 4 & $\begin{array}{l}\text { Omar is in } \\
\text { Australia }\end{array}$ & Animais em extinção & $\begin{array}{l}\text { Campanhas de proteção } \\
\text { aos animais. }{ }^{12}\end{array}$ & $\begin{array}{l}\text { Análisar campanhas } \\
\text { de proteção aos } \\
\text { animais. }\end{array}$ & $\begin{array}{l}\text { Elaboração de uma } \\
\text { campanha sobre proteção de } \\
\text { animais em extinção. } \\
\text { Postar no Instagram e } \\
\text { compartilhar em grupos do } \\
\text { What's App }\end{array}$ & $\begin{array}{l}\text { a) TED-Ed Lesson }{ }^{13} \\
\text { b) Crello }\end{array}$ \\
\hline 5 & $\begin{array}{l}\text { Omar goes to } \\
\text { the Middle East }\end{array}$ & Culinária local & $\begin{array}{lr}\text { Documentário: } & \text { Middle } \\
\text { Eastern } & \text { Food } \\
\text { Documentary }^{14} & \end{array}$ & $\begin{array}{l}\text { Trabalhar aspectos } \\
\text { lexicais utilizando } \\
\text { elementos da } \\
\text { culinária local. }{ }^{15} \\
\text { Refletir sobre } \\
\text { aspectos culturais. }\end{array}$ & $\begin{array}{l}\text { Aula prática de culinária. } \\
\text { Compartilhar com outras } \\
\text { turmas. }\end{array}$ & $\begin{array}{l}\text { a) Quizlet }{ }^{16} \\
\text { b) Educational Games } \\
17 \\
\text { c) Quizizz }{ }^{18}\end{array}$ \\
\hline 6 & $\begin{array}{l}\text { Omar explores } \\
\text { Africa! }\end{array}$ & $\begin{array}{l}\text { Cultura Africana no } \\
\text { Brasil }\end{array}$ & $\begin{array}{l}\text { Música: Waka Waka da } \\
\text { Shakira }^{19}\end{array}$ & $\begin{array}{lr}\text { Refletir } & \text { sobre } \\
\text { contrastes } & \text { e } \\
\text { semelhanças } & \text { das } \\
\text { culturas Africanas e } \\
\text { Brasileiras. }\end{array}$ & $\begin{array}{l}\text { Gravar um Podcast sobre } \\
\text { semelhanças e contrastes } \\
\text { entre cultura Africana e } \\
\text { Brasileira. }\end{array}$ & $\begin{array}{l}\text { a) Kahoot }{ }^{20} \\
\text { b) Live Worksheets } \\
\text { c) Buzzsprout } \\
\text { d) Mind Maps }\end{array}$ \\
\hline 7 & $\begin{array}{l}\text { Omar faces the } \\
\text { ocean! }\end{array}$ & $\begin{array}{lr}\text { Educação } & \text { emocional } \\
\text { (como } & \text { enfrentar } \\
\text { nossos } & \text { oceanos } \\
\end{array}$ & $\begin{array}{l}\text { Vídeo: How to process } \\
\text { your emotions }{ }^{21}\end{array}$ & $\begin{array}{l}\text { Refletir sobre como } \\
\text { lidamos com nossas } \\
\text { emoções e o que }\end{array}$ & $\begin{array}{lcl}\text { Criação } & \text { de } & \text { Stickers de } \\
\text { What's App } & \text { para serem } \\
\text { enviados com } & \text { o intuito de }\end{array}$ & $\begin{array}{l}\text { a) TED-Ed Lesson }{ }^{22} \\
\text { b) Sticker Pack }\end{array}$ \\
\hline
\end{tabular}

9 Videoclipe disponivel em: https://www.youtube.com/watch?v=g4liccUjGps.

${ }^{10}$ Atividade da música disponivel em: https://lyricstraining.com/en/play/alicia-keys/empire-state-of-mind-part-ii-broken-downlive/HuRFPTXHJu

11 O professor deve selecionar algumas imagens de acordo com a faixa etária e nível linguístico do público alvo, além de filtrar informações relevantes para a discussão proposta. Exemplos disponíveis em: https://br.pinterest.com/lirpastar1979/technology-comics/

${ }_{12}$ Exemplos disponíveis em: https://www.worldanimalprotection.org/wildlife-not-entertainers/latest-campaign-news

${ }^{13}$ Lição disponível em: https://ed.ted.com/lessons/when-will-the-next-mass-extinction-occur-borths-d-emic-and-pritchard

14 Vídeo do documentário disponível em: https://www.youtube.com/watch?v=czg3rOhWB8E

${ }^{15}$ Sugestões: a) 20 Top Middle Eastern Foods: Which is the best? Disponivel em: https://edition.cnn.com/travel/article/middleeast-food-dishes/index.html; b) 32 Middle Eastern recipes you can make at home. Disponível em: https://www.middleeasteye.net/discover/32-middle-east-recipes-make-at-home; c) Top Middle Eastern Recipes for Beginners. Disponivel em: https://www.thespruceeats.com/middle-eastern-recipes-for-beginners-2355793.

${ }^{16}$ Atividade específica disponível em: https://quizlet.com/442509189/cooking-skills-flash-cards/

${ }_{17}$ Repositório disponível em: https://www.culinaryschools.org/kids-games/

${ }^{18}$ Atividade específica disponivel em: https://quizizz.com/join/quiz/56434d30fdd032966cff2b0d/start?studentShare=true

19 Videoclipe disponível em: https://www.youtube.com/watch?v=pRpeEdMmmQ0

${ }^{20}$ Atividade especifica disponível em: https://create.kahoot.it/details/african-society-and-culture/65857241-b208-4b99-ba8d1 e8452811f75

${ }^{21}$ Vídeo disponivel em: https://www.youtube.com/watch?v=b197XOd9S7U\&t=35s

${ }^{22}$ Lição disponivel em: https://ed.ted.com/lessons/does-stress-cause-pimples-claudia-aguirre. 


\begin{tabular}{|c|c|c|c|c|c|c|}
\hline & & pessoais) & & $\begin{array}{l}\text { podemos fazer para } \\
\text { melhorar a maneira } \\
\text { que lidamos com elas } \\
\text { e com a do próximo. }\end{array}$ & fazer alguém sorrir. & \\
\hline 8 & $\begin{array}{l}\text { Omar goes back } \\
\text { to Brazil! }\end{array}$ & Cultura indígena & $\begin{array}{l}\text { Artigo online: } \\
\text { Brazil's indigenous } \\
\text { people: 'We fight for the } \\
\text { right to exist' }\end{array}$ & $\begin{array}{l}\text { Pesquisar, Analisar e } \\
\text { Refletir sobre a } \\
\text { cultura indígena no } \\
\text { Brasil. }\end{array}$ & $\begin{array}{l}\text { Debate sobre o posiciona- } \\
\text { mento poítico brasileiro em } \\
\text { relação às terras indígenas. }\end{array}$ & $\begin{array}{l}\text { a) Mentimeter } \\
\text { b) Wheel Decide }\end{array}$ \\
\hline
\end{tabular}

Quadro 1. Organização categórica de propostas de atividades.

Fonte: Elaborado pelas autoras.

\begin{tabular}{|c|c|c|}
\hline FERRAMENTA DIGITAL & DESCRIÇÃO & ACESSO \\
\hline BUZZSPROUT & $\begin{array}{l}\text { É uma ferramenta online com instruções que auxiliam na criação de } \\
\text { Podcasts }^{24} \text {. }\end{array}$ & $\begin{array}{l}\text { Disponível em: } \\
\text { https://www.buzzsprout.co } \\
\underline{\mathrm{m} /}\end{array}$ \\
\hline CANVA & $\begin{array}{l}\text { Canva é uma plataforma de design gráfico que permite aos usuários criar } \\
\text { gráficos de mídia social, apresentações, pôsteres e outros conteúdos } \\
\text { visuais. Está disponível online e em dispositivos móveis e integra } \\
\text { milhões de imagens, fontes, modelos e ilustrações. }\end{array}$ & $\begin{array}{l}\text { Disponível em: } \\
\underline{\text { https://www.canva.com/ }}\end{array}$ \\
\hline CRELLO & $\begin{array}{l}\text { A Crello é uma ferramenta de design online para criar animações e } \\
\text { gráficos para redes sociais e Internet. }\end{array}$ & $\begin{array}{l}\text { Disponível em: } \\
\underline{\text { https://crello.com/pt/ }}\end{array}$ \\
\hline GOOGLE EARTH & $\begin{array}{l}\text { Google Earth é um programa de computador desenvolvido e distribuído } \\
\text { pela empresa estadunidense do Google cuja função é apresentar um } \\
\text { modelo tridimensional do globo terrestre, construído a partir de mosaico } \\
\text { de imagens de satélite. }\end{array}$ & $\begin{array}{l}\text { Disponível em: } \\
\text { https://www.google.com.b } \\
\underline{\text { r/intl/pt-BR/earth/ }}\end{array}$ \\
\hline GOOGLE STREET VIEW & $\begin{array}{l}\text { Google Street View é um recurso que disponibiliza vistas panorâmicas } \\
\text { de } 360^{\circ} \text { na horizontal e } 290^{\circ} \text { na vertical e permite que os usuários vejam } \\
\text { partes de algumas regiões do mundo ao nível do chão/solo. }\end{array}$ & $\begin{array}{l}\text { Disponível em: } \\
\text { https://www.google.com.b } \\
\underline{\mathrm{r} / \mathrm{maps} / \text { preview }}\end{array}$ \\
\hline KAHOOT! & $\begin{array}{l}\text { Kahoot! é uma plataforma de aprendizado baseada em jogos, usada } \\
\text { como tecnologia educacional em escolas e outras instituições de ensino. } \\
\text { Seus jogos de aprendizado, Kahoots, são testes de múltipla escolha que } \\
\text { podem ser acessados por meio de um navegador da Web ou do aplicativo } \\
\text { Kahoot. }\end{array}$ & $\begin{array}{l}\text { Disponível em: } \\
\underline{\text { https://kahoot.com/schools }} \\
\underline{\underline{-\mathrm{u} /}}\end{array}$ \\
\hline LIVEWORKSHEETS & $\begin{array}{l}\text { Liveworksheets permite que o professor transforme atividades que } \\
\text { seriam impressas (em formato doc, pdf, jpg...) em exercícios interativos } \\
\text { online. Os exercícios podem apresentar opções de auto-correção, ou } \\
\text { podem ser enviados ao professor. As atividades podem incluir o anexo } \\
\text { de sons, vídeos, exercícios gamificados, de múltipla escolha, e até } \\
\text { atividades para prática de produção oral, onde os alunos utilizam o } \\
\text { microfone do computador. }\end{array}$ & $\begin{array}{l}\text { Disponível em: } \\
\text { https://www.liveworksheet } \\
\underline{\text { s.com/aboutthis_en.asp }}\end{array}$ \\
\hline LYRICS TRAINING & $\begin{array}{l}\text { Lyrics Training é um website que permite a realização de atividades com } \\
\text { músicas, como exercícios de completar lacunas e karaokê. }\end{array}$ & $\begin{array}{l}\text { Disponível em: } \\
\text { https://lyricstraining.com/ }\end{array}$ \\
\hline MENTIMETER & $\begin{array}{l}\text { A Mentimeter é uma empresa sueca com sede em Estocolmo que } \\
\text { desenvolve e mantém um aplicativo de mesmo nome usado para criar } \\
\text { apresentações com feedback em tempo real. }\end{array}$ & $\begin{array}{l}\text { Disponível em: } \\
\underline{\text { https://www.mentimeter.c }} \\
\underline{\mathrm{om} /}\end{array}$ \\
\hline MINDMEISTER & $\begin{array}{l}\text { O MindMeister é um aplicativo de mapeamento mental online que } \\
\text { permite que seus usuários visualizem, compartilhem e apresentem seus } \\
\text { pensamentos através da nuvem. }\end{array}$ & $\begin{array}{l}\text { Disponível em: } \\
\underline{\text { www.mindmeister.com }}\end{array}$ \\
\hline PADLET & $\begin{array}{l}\text { Padlet é uma ferramenta online que permite a criação de um mural ou } \\
\text { quadro virtual dinâmico e interativo para registrar, guardar e partilhar } \\
\text { conteúdos multimídia. Funciona como uma folha de papel, onde se pode } \\
\text { inserir qualquer tipo de conteúdo (texto, imagens, vídeo, hiperlinks) } \\
\text { juntamente com outras pessoas. Com a mesma conta pode-se criar vários }\end{array}$ & $\begin{array}{l}\text { Disponível em: } \\
\text { https://pt-br.padlet.com/ }\end{array}$ \\
\hline
\end{tabular}

${ }^{23}$ Disponivel em: https://www.bbc.com/news/world-latin-america-48050717

24 "Conjunto de arquivos publicados pela mídia digital, composto de músicas, vídeos, notícias, que ficam armazenados em um servidor na internet, sujeito a atualizações constantes, e que podem ser automaticamente baixados para um computador ou transferidos para aparelhos de informática portáteis" (MICHAELIS, Dicionário Brasileiro da Língua Portuguesa). Disponível em: https://michaelis.uol.com.br/moderno-portugues/busca/portugues-brasileiro/podcast/.

LínguaTec, Instituto Federal de Educação, Ciência e Tecnologia do Rio Grande do Sul, Bento Gonçalves v. 5 , n. 2 , p. 149-168, nov. 2020. 


\begin{tabular}{|c|c|c|}
\hline & murais. (SEAD, 2018 ${ }^{25}$ ) & \\
\hline QUIZLET & 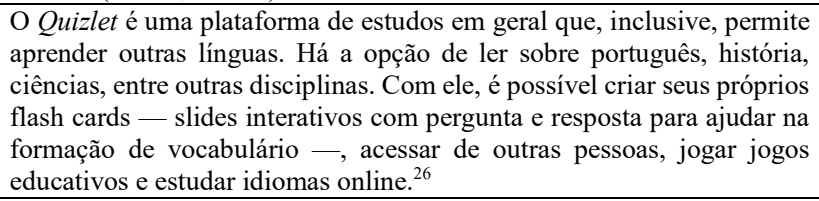 & $\begin{array}{l}\text { Disponível em: } \\
\text { www.quizlet.com }\end{array}$ \\
\hline QUIZZIZ & $\begin{array}{l}\text { O Quizizz é um software que permite usar e criar "Quizes" para jogar em } \\
\text { sala de aula ou como trabalho de casa. }{ }^{27}\end{array}$ & $\begin{array}{l}\text { Disponível em: } \\
\text { www.quizziz.com }\end{array}$ \\
\hline STICKER PACKS & $\begin{array}{l}\text { O Sticker Packs for WhatsApp é um pacote de adesivos nativos do } \\
\text { Telegram para usar no WhatsApp, disponível para Android e iOS. }\end{array}$ & $\begin{array}{l}\text { Disponível em: } \\
\underline{\text { https://getstickerpack.com// }} \\
\underline{\text { stickers }}\end{array}$ \\
\hline TED-ED & $\begin{array}{l}T E D-E d \text { é uma plataforma online que contém uma curadoria de vídeos } \\
\text { da plataforma TED e animações próprias. O website oferece lições } \\
\text { prontas sobre temas diversificados com opções de vídeo, compreensão, } \\
\text { discussão e pensamento crítico. A plataforma também permite a } \\
\text { customização de lições pelos professores. }\end{array}$ & $\begin{array}{l}\text { Disponível em: } \\
\underline{\text { https://ed.ted.com/ }}\end{array}$ \\
\hline WHEELDECIDE & $\begin{array}{l}\text { Wheel Decide é uma ferramenta simples criada a partir da típica roda da } \\
\text { sorte, que permite a criação de diferentes rodas. }\end{array}$ & $\begin{array}{l}\text { Disponível em: } \\
\underline{\text { https://wheeldecide.com/ }}\end{array}$ \\
\hline YOUTUBE & Youtube é uma plataforma de compartilhamento de vídeos. & $\begin{array}{l}\text { Disponível em: } \\
\text { www.youtube.com }\end{array}$ \\
\hline
\end{tabular}

Quadro 2. Informações sobre as ferramentas digitais propostas para utilização.

Fonte: Elaborado pelas autoras.

As proposições compartilhadas nos quadros apresentados visam ao enfoque comunicativo e intercultural no ensino de línguas, suscitando ponderações e reflexões quanto ao uso de língua estrangeira em diferentes contextos culturais. A interação por meio de atividades e ferramentas multimodais participam da busca pela construção do caráter social do aluno como cidadão consciente. Sugere-se que as atividades sejam realizadas parcialmente fora do horário de aula, e parcialmente em horário de aula, visando à aplicabilidade do conceito de Sala de Aula Invertida (SAI). Dessa forma, os alunos terão a chance de conhecer um pouco mais sobre o conteúdo e a plataforma escolhida, exercendo sua capacidade de agência e autonomia no ritmo que desejarem e que for conveniente para seu aprendizado, estimulando a interação aluno/tecnologia. Já os momementos em sala de aula (virtual ou não), serão focados em interações aluno/aluno e aluno/professor, estimulando a prática e a produção na língua estrangeira/adicional, e o esclarecimento de quaisquer dúvidas que possam vir a surgir, exibindo o papel do professor como mediador durantes as aulas.

A introdução e aplicação destas atividades podem apresentar algumas limitações quanto à conexão com a internet. Além disso, no início da inserção dessas propostas pedagógicas, os alunos podem encontrar dificuldade ao lidar com algumas ferramentas e plataformas aqui sugeridas. Apesar de

\footnotetext{
25 Tutorial disponível em: https://inovaeh.sead.ufscar.br/wp-content/uploads/2019/04/Tutorial-Padlet.pdf

26 Fonte: https://www.techtudo.com.br/tudo-sobre/quizlet.html; Tutorial disponível em: http://www.gestaoescolar.diaadia.pr.gov.br/arquivos/File/pdf/tutorial_quizlet.pdf

27 Tutorial disponível em: https://ceduc.unifei.edu.br/tutoriais/quizizz-como-criar-um-quiz/
}

LínguaTec, Instituto Federal de Educação, Ciência e Tecnologia do Rio Grande do Sul, Bento Gonçalves v. 5 , n. 2 , p. $149-168$, nov. 2020. 
serem considerados por alguns teóricos, como Prensky (2001), "nativos digitais", temos acompanhado no processo eduacional vigente que isso não é inteiramente verdadeiro. Devido à falta de acesso a certos recursos tecnológicos, mesmo pertencendo a uma geração considerada "conectada", grande parte dos alunos pode demonstrar certo grau de dificuldade. Por isso, salienta-se o papel do professor em auxiliar e incentivar o uso dessas plataformas, de maneira a aumentar o nível de letramento digital dos alunos e propiciar uma experiência mais completa e eriquecedora neste contexto pandêmico.

Por outro lado, as propostas aqui apresentadas têm o potencial de alcançar melhoria no processo de ensino e aprendizagem da língua estrangeira/adicional. Ao fazerem uso de recursos interativos e tecnológicos, como os sugeridos, os alunos têm a oportunidade de lidar com a língua-alvo de modo lúdico e variado, além de ter contato com diferentes modos de representação, contribuindo para a construção mais crítica de sentido e significado.

\section{Considerações finais}

O presente artigo teve como objetivo refletir sobre o papel das tecnologias digitais de informação e comunicação (TDICs) no ensino de línguas estrangeiras/adicionais nas atuais circunstâncias em meio a um fenômeno internacional inédito. Consequentemente, alguns conceitos relacionados ao ensino de línguas na contemporaneidade, como Atividade Social (LIBERALI, 2009), Interculturalidade (DURÃO, 2002), Letramento Digital (XAVIER, 2011) e Multiletramentos (COPE; KALANTZIS, 2000) foram abordados, enfatizando a relação professor/tecnologia/aprendizagem via mediação e interação. Sugerimos, também, oito atividades pedagógicas com diferentes propostas de ação social e recursos multimodais, envolvendo o uso de ferramentas digitais a título de exemplificação de práticas pedagógicas, conforme apresentamos no primeiro quadro.

Acreditamos que aprender línguas estrangeiras/adicionais não envolve somente transitar entre suas dimensões sistêmicas e funcionais, mas também por entre suas dimensões críticas e sociais. Ao ponderar sobre conteúdos abordados, destacamos a necessidade da atenção perante a inclusão de matizes culturais nas aulas de línguas estrangeiras/adicionais (FERREIRA, 2020), para que os aprendizes incorporem a prática intercultural por meio do uso da linguagem, a fim de contrastar com sua própria cultura, promovendo um novo olhar sobre si.

Por conseguinte, conforme mencionamos anteriormente, observados todos esses aspectos, entendemos que quando as novas tecnologias são ambientadas no contexto educacional, podem respaldar o princípio de novas realidades, expandindo o conhecimento tanto do aluno quanto do professor. A partir disso, há o despertar de novos interesses, juntamente com o desenvolvimento de 
habilidades e dos multiletramentos. Conforme Oliveira e Souza (2020, p. 9), diante dessas considerações, percebe-se que "a necessidade de se reinventar é premente em tempos de crise".

Concluímos este artigo na esperança de que, mediante as sugestões didáticas apresentadas, seja possível contribuir para maior clareza na concepção do uso de recursos midiáticos para trabalhar aspectos linguísticos, culturais e sociais da língua estrangeira de forma mais significativa e motivadora.

\section{Referências}

ALMEIDA, L. B.; PAULA, L. G. O retrato da exclusão digital na sociedade brasileira. Revista de Gestão da Tecnologia e Sistemas de Informação, v. 2, n. 1, p. 55-67, 2005.

AMIEL, T.; SANTOS, K. Uma análise dos termos de uso de repositórios de recursos educacionais digitais no Brasil. Trilha Digital, v.1, p.118-133, 2013. Disponível em: http://ead.mackenzie.br/; Acesso em: 20 mai. 2020.

ARAÚJO, M. A. F. de; FIGUEIREDO, F. J. Q. de. Cultura, interculturalidade e sala de aula de língua estrangeira: múltiplas perspectivas. REVELLI - Revista de Educação, Linguagem e Literatura, v.7, n.1, Junho, 2015, p. 63-76.

ARAÚJO, N. M. S. Avaliação de objetos de aprendizagem para o ensino de língua portuguesa: análise de aspectos tecnológicos ou didático-pedagógicos? In: ARAÚJO, J. C.; ARAÚJO, N. M. S. (Org.). EaD em tela: docência, ensino e ferramentas digitais. 1ed. Campinas: Pontes, 2013, v. 1, p. 179-207.

BAKHTIN, M. Estética da criação verbal. São Paulo: Martins Fontes, 2000.

BARROS, D. M. V.; OKADA, A.; KENSKI, V. Coletividade aberta de pesquisa: os estilos de coaprendizagem no cenário online. "Educação, Formação \& Tecnologias". Vol. 5, n. 02, 2012, p. 11-24.

BELLINI, C. G. P.; GIEBELEN, E.; CASALI, R. R. B. Limitações digitais. Informação \& Sociedade, v. 20, n. 2, p. 25-35, 2010.

BELLONI, M. L. O que é mídia-educação. 2. ed. Campinas, SP: Autores associados, 2005.

BENVENISTE, É. Da subjetividade na linguagem: problemas de linguística geral I. 4. ed. Campinas: Pontes, 2008.

BERGMANN, J; SAMS, A. Flip Your Classroom: reach every student in every class every day. Learning, Innovation \& tech. Eugene, Oregon: ISTE, 2012.

BRAGA, J. C.; MENEZES, L. Introdução aos Objetos de Aprendizagem. In: BRAGA, J. C. (Org). Objetos de Aprendizagem - Volume 1: Introdução e Fundamentos. Santo André: Editora da UFABC, 2014.

BRASIL. Portaria N 343, de 17 de março de 2020. Dispõe sobre a substituição das aulas presenciais por aulas em meios digitais enquanto durar a situação de pandemia do Novo Coronavírus - COVID-19. 
D.O.U 18/03/2020. Disponível em: <http://www.in.gov.br/en/web/dou/-/portaria-n-343-de-17-de-marcode-2020-248564376>. Acesso em: 19 mai. 2020.

BRENER, Fernanda Machado. Práticas de letramentos literários multimodais na formação do professor. 165 f. 2018. Tese de Doutorado. Universidade Estadual de Maringá (UEM), Maringá, 2018. Disponível em: http://www.ple.uem.br/defesas/def_fernanda machado_brener_do.html. Acesso em: 05 nov. 2020.

CAMARGO, L. Ilustração do livro infantil. Belo Horizonte: Lê, 1995.

CAZDEN, C. et al. A Pedagogy of Multiliteracies: Designing Social Futures. Harvard Educational Review, v. $66, \quad$ n. $1, \quad$ p. $60-92$, Spring 1996. Disponível em: http://newarcproject.pbworks.com/f/Pedagogy+of+Multiliteracies_New+London+Group.pdf. Acesso em: 27 setembro 2020.

CELANI, Maria Antonieta Alba. Culturas de aprendizagem: risco, incerteza e educação. In: MAGALHÃES, Maria Cecília (org.). A formação do professor como um profissional crítico: linguagens e reflexão. Campinas, SP: Mercado de Letras, 2004, p. 37-56.

CENTENARO, F. K.; REIS, S. C. dos. Jogos digitais em sala de aula de Língua Inglesa: investigação de uma proposta de gestão pedagógica para o ensino. Linguagem \& Ensino, Pelotas, v. 20, n. 1, 2017, p. 35-60. Disponível em: https://periodicos.ufpel.edu.br/ojs2/index.php/rle/article/view/15216/9410. Acesso em: 09 outubro 2020.

CONSELHO DA EUROPA, 2002. Quadro Europeu Comum de Referência para as Línguas: aprendizagem, ensino e avaliação. Disponível em: https://area.dge.mec.pt/gramatica/Quadro_Europeu_total.pdf. Acesso em: 24 abr. 2020.

COPE, B.; KALANTZIS, M. Multiliteracies: literacy learning and the design of social futures. London: Routledge, 2000.

CORREAA, H. T.; DIAS, D. R. Multiletramentos e usos das tecnologias digitais da informação e comunicação com alunos de cursos técnicos. Trabalhos em Linguística Aplicada. Vol. 55, n. 02, Campinas, 2016, p. 241-261. Disponível em: https://www.scielo.br/pdf/tla/v55n2/0103-1813-tla-55-0200241.pdf. Acesso em: 09 outubro 2020.

DE MATTOS, F.A.M.; CHAGAS, G.J.N. Desafios para a inclusão digital no Brasil. Perspectivas em Ciência da Informação, v. 13, n. 2, 2008, p. 67-94.

DOTTA, S. C. et al. Abordagem dialógica para a condução de aulas síncronas em uma webconferência. In: X Congresso Brasileiro de Ensino Superior a Distância, 2013, Belém. Anais do X Congresso Brasileiro de Ensino Superior a Distância. Belém: Unirede/UFPA, 2013.

DURÃO, Adja Balbino de Amorim Barbieri. Psiu? Você quer saber mais sobre as línguas? (5) Folha Nossa. Ano 2. n.12. Julho, 2002. p. 6-7.

ENGESTRÖM, Y. Aprendizagem por expansão na prática: em busca de uma reconceituação a partir da teoria da atividade. Tradução D. Vilas Boas e M. Damiani. In: Cadernos de Educação. Pelotas: Ed. UFPel, 2002. 
FERREIRA, C. C. Abre alas que eu quero passar. Não só a festividades se resume trabalhar (inter/trans)culturalidade: reflexões teóricas e propostas pedagógicas. In: FERREIRA, C. C.; MIRANDA, C. V. M. (Orgs.) (Re)Visões sobre o processo de ensino e aprendizagem de línguas estrangeiras/adicionais: conjugação entre teoria e prática. 1. Ed. Campinas, SP: Pontes Editores, 2020, p. 13-56.

FERREIRA, C. C. Encantamento e reflexões à luz do imagético: a narrativa visual na contação de histórias. In: MIRANDA, C. V. M.; FERREIRA, C. C. C. (Orgs.) Reflexões, diálogos e perspectivas sobre literatura e ensino. Campinas, SP: Pontes Editores, 2019, p. 129-164.

FREITAS, M. T. Letramento digital e formação de professores. Educação em Revista, n. 26, 2010, p. 335-352.

GARCIA, C. B.; SILVA, F. D. S.; FELÍCIO, R. P. Projet(o) arte: uma proposta didática. In: ROJO, R. H. R.; MOURA, E. Multiletramentos na escola. São Paulo: Parábola Editorial, 2012.

GIMENEZ, T. Eles comem corn flakes, nós comemos pão com manteiga: espaços para a reflexão sobre cultura na sala de aula de língua estrangeira. Anais do IX Encontro de Professores de Línguas Estrangeiras - IX EPLE. Londrina: APLIEPAR, 2001. p. 107-114.

GODZICKI, L., GODZICKI, N., KROFEL, M.; MICHAELS, R. Increasing motivation and engagement in elementary and middle school students through technology-supported learning environments, 2013.

INDALÉCIO, A.; RIBEIRO, M. Gerações Z e Alfa: os novos desafios para a educação contemporânea. Revista UNIFEV: Ciência \& Tecnologia, v. 2, p. 137-148, 2017.

JUNIOR, V.; MONTEIRO, J. Educação e covid-19: as tecnologias digitais mediando a aprendizagem em tempos de pandemia. Revista Encantar - Educação, Cultura e Sociedade - Bom Jesus da Lapa, v. 2, 2020, p. 01-15. Disponível em: http://www.revistas.uneb.br/index.php/encantar/article/view/8583. Acesso em: 19 mai. 2020.

KALANTZIS, M; COPE, B. Literacies. New York, Port Melbourne: Cambridge University Press, 2012.

KALANTZIS, M; COPE, B. New Learning: elements of a science of education. New York, Port Melbourne: Cambridge University Press, 2008.

KRESS, G., van LEEUWEN, T. Reading images: the grammar of visual design. (2ed.). 2010, p. 101-116.

LEFFA, V. J. Língua estrangeira: ensino e aprendizagem. Pelotas: EDUCAT, 2016.

LEFFA, V. J.; IRALA, V. B. O ensino de outra(s) língua(s) na contemporaneidade: questões conceituais e metodológicas. In: LEFFA, V. J.; IRALA, V. B. (Orgs.). Uma espiadinha na sala de aula: ensinando línguas adicionais no Brasil. Pelotas: Educat, 2014, p. 21-48.

LÉVY, Pierre. Cibercultura. 3. ed. São Paulo: Editora 34, 2010.

LIBERALI, F. C. As linguagens da reflexão. In: MAGALHÃES, M.C.M. (org.) A Formação do professor como um profissional reflexivo. São Paulo, EDUC. Coleção Faces da Lingüística Aplicada, 2004. 
LIBERALI, F. C. Atividade social nas aulas de língua estrangeira. São Paulo, Moderna, 2009.

LOPES, D.V. As novas tecnologias e o ensino de língua estrangeira, Recife, PE, 2012.

MARQUES, E. Utilização de jogos no processo de ensino/aprendizagem. Criciúma, 2016.

MARTINS, C. Omar e o Mar. Dimensão, 2015.

MARX, K. Manuscritos econômicos-filosóficos. In: FERNANDES, F. (org.). Marx e Engels: história. São Paulo: Ática, p. 147-181 (Coleção Grandes Cientistas Sociais), 1989.

MORAN, J. Mudando a educação com metodologias ativas. In: Coleção Mídias Contemporâneas. Convergências Midiáticas, Educação e Cidadania: aproximações jovens. Vol. II. Carlos Alberto de Souza e Ofelia Elisa Torres Morales (orgs.). PG: Foca Foto-PROEX/UEPG, 2015, p. 15-33.

NORTON, B.; TOOHEY, K. Critical pedagogies and language learning: An introduction. In: NORTON, B.; TOOHEY, K. Critical pedagogies and language learning. Cambridge University Press: Cambridge, 2004, p. 1-19.

OLIVEIRA, H. V.; SOUZA, F. S. Do conteúdo programático ao sistema de avaliação: reflexões educacionais em tempos de pandemia (COVID-19). Boletim de Conjuntura, Ano II, vol. 2, n. 5. Boa Vista, 2020. Disponível em: https://revista.ufrr.br/boca/article/view/OliveiraSouza. Acesso em: 20 mai. 2020.

PADILHA, E. C.; SELVERO, C. M. Crenças sobre o uso do material didático no ensino de línguas estrangeiras. Revista Linguagem, 21.ed., 2013.

PALFREY, J.; GASSER, U. Nascidos na era digital: entendendo a primeira geração de nativos digitais. Porto Alegre: ArtMed, 2011.

PASSOS, E. C. B.; SOARES, C. V. C. de. Sala de aula invertida e as tecnologias digitas no ensino de leitura em língua inglesa sob a ótica dos multiletramentos. Fólio - Revista de Letras, v. 11, n. 1, 2019, p. 821-843. Disponível em: https://core.ac.uk/download/pdf/236654042.pdf. Acesso em: 09 out. 2020.

PRENSKY, M. Nativos Digitais, Imigrantes Digitais. In: On the Horizon. NCB University Press, Vol. 9, n. 05, 2001.

ROCHA, C. H.; TíLIO, R. C. As dimensões da linguagem em livros didáticos de inglês para o ensino fundamental I. Trabalhos em Linguística Aplicada (UNICAMP), v. 48, p. 295-316, 2009.

RODRIGUES, Maria Lúcia Costa. A narrativa visual na literatura infantil brasileira: histórico e leituras analíticas. Joinville, SC: Univille, 2012.

ROJO, H. R. Entre Plataformas, ODAs e Protótipos: Novos multiletramentos em tempos de WEB2. Campinas, SP: Pontes, 2016b.

ROJO, Roxane (org.). Escola conectada. Os multiletramentos e as TICS. São Paulo: Parábola, 2012.

ROJO, Roxane. Letramentos múltiplos, escola e inclusão social. São Paulo: Parábola, 2009. 
SILVA, S. P. Letramento digital e formação de professores na era da web 2.0: o que, como e por que ensinar? Hipertextus Revista Digital, Recife, n. 8, jun. 2012. Disponível em: <http://www.hipertextus.net/volume8/01-Hipertextus-Vol8-Solimar-Patriota-Silva.pdf>. Acesso em: 04 nov. 2020.

UNESCO. Organização das Nações Unidas para a Educação, a Ciência e a Cultura, 2020. Disponível em: <https://nacoesunidas.org/agencia/unesco/>. Acesso em: 19 mai. 2020.

UNICEF. Fundo das Nações Unidas para a Infância, 2020. Disponível em: <https://www.unicef.org/brazil/>. Acesso em: 19 mai. 2020.

VYGOTSKY, L. S. A formação social da mente. São Paulo: Martins Fontes, 1984.

WARSCHAUER, Mark. Tecnologia e inclusão social: a exclusão social em debate. Carlos Szlak (trad.). São Paulo: SENAC, 2006.

XAVIER, A. C. (2011). Letramento digital: impactos das tecnologias na aprendizagem da Geração Y. Revista Calidoscópio. vol. 9, n. 1, pp. 3-14.

YOSHIDA, E. Um dia da educação sem aulas para a maioria dos estudantes. Exame, 28 abr. 2020. Disponível em: https://exame.com/mundo/um-dia-da-educacao-sem-aulas-para-a-maioria-dosestudantes/. Acesso em: 19 mai. 2020.

ZAVALA, V. Language as social practice: deconstructing boundaries in intercultural bilingual education. Trabalhos em Linguística Aplicada, 57(3), 2018, p. 1313-1338 Disponível em: <https://doi.org/10.1590/010318138653255423542>. Acesso em: 11 maio 2020.

Data de submissão: 03/09/2020. Data de aprovação: 23/10/2020. 